\title{
EPIDEMIOLOGICAL STUDY OF PREMATURE EXTRACTION OF 5-6-YEAR-OLD CHILDREN FROM NORTHEASTERN BULGARIA
}

\author{
Radosveta Andreeva ${ }^{1}$, Hristina Arnautska ${ }^{2}$, Tihomir Georgiev ${ }^{3}$ \\ ${ }^{1}$ Department of Pediatric Dentistry, Faculty of Dental Medicine, \\ Medical University of Varna \\ ${ }^{2}$ Department of Orthodontics, Faculty of Dental Medicine, Medical University of Varna \\ ${ }^{3}$ Department of Oral and Maxillofacial Surgery, Faculty of Dental Medicine, \\ Medical University of Varna
}

\begin{abstract}
Primary teeth lost one or more years before the time of their physiological exfoliation are prematurely lost. The aim of this study is to show the percentage of prematurely extracted teeth of urban and rural children, the types of the prematurely lost teeth and the reasons for their early loss. Subject of monitoring of the epidemiological research were $\mathbf{1 2 0 0}$ children (half of them are from urban regions and the other half are from rural areas) examined by strictly calibrated teams of dental specialists. The DMF $(T+t)$ index is used to measure the dental health. We calculated the missing teeth associated with the age of the children. The teeth we considered as prematurely lost were extracted one or more years before the time of their physiological exfoliation. The percentage of prematurely extracted teeth is $\mathbf{4 . 6}$. There was a statistically significant difference in the relative shares of the prematurely extracted teeth of the urban (3.67\%) and the rural children (5\%). The second molars are the most often extracted primary teeth both for the rural $(61.67 \%)$ and the urban children (57.7\%), followed by the first molars $-35.29 \%$ for the rural and $34.41 \%$ for the urban children. The canines are the most rarely prematurely extracted teeth $-\mathbf{2 . 4 9 \%}$ for rural children, $7.7 \%$ for urban children.

The main reason for early tooth loss is the carious lesion - in $\mathbf{9 4 . 1 2 \%}$ and in only $5.89 \%$ - other reasons. This result demonstrates the connection between premature extraction of the primary teeth, carious activity and the need of prophylaxis.
\end{abstract}

Keywords: premature extraction of teeth, prevalence, primary teeth, carious lesions

Address for correspondence:

Radosveta Andreeva

Faculty of Dental Medicine,

Medical University of Varna

55 Marin Drinov Str.

9002 Varna, Bulgaria

e-mail:doctor_ra@abv.bg

Received: May 9, 2016

Accepted: June 24, 2016

\section{INTRODUCTION}

In the year 2010 a dental survey concerning children's oral health was carried out in the Northeastern region of Bulgaria. Early primary tooth loss registration was a part of this study. Early tooth loss can be a result of tooth decay and its complications or caused by other reasons - traumas, periodontal diseases, etc. Premature loss of primary teeth is very of- 
Radosveta Andreeva, Hristina Arnautska, Tihomir Georgiev

ten the cause of a number of aesthetic, functional and orthodontic problems in children.

Epidemiological surveys have found that about $15 \%$ of school children sustain early tooth loss. The premature extraction of primary teeth accounts for $4.3 \%$ to $16.5 \%$ of all cases in the different studies $(1,2,3,5,6)$. Premature extraction of primary teeth has been found to increase in many countries, which makes it a serious dental and social problem for the dental health of children.

The wide range of the data for the prevalence of premature tooth extraction reported in the epidemiological studies is most probably due to the variability of factors such as the socio-economic status of the population, caries prevalence, oral hygiene, usage of fluoridated water, the treatment philosophy of the dentist, geographic and behavioural differences between the investigated regions and between the different countries $(4,7,8)$. Dearing S.G. reported prevalence of $16.5 \%$ of prematurely extracted primary teeth in Saudi Arabia and 9.28\% in Brazil $(5,6,7,8)$. In Istanbul, the prevalence of premature extraction among children with mixed dentition is about $25 \%$ (9). The data in Bulgaria on the prevalence of premature dental extraction in school children varies between 4.3 to 9.7 percent in the different publications $(3,4)$.

The aim of this study is to show the percentage of prematurely extracted teeth of urban and rural children, the types of the prematurely lost teeth and the reasons for their early loss.

\section{MATERIALS AND METHODS}

The number of the children included in the study is 1200.600 of them are from urban regions and the other 600 are from rural areas. All of them are 6-7 years old. They are examined by strictly calibrated teams of dental specialists. Before the examination started, parents were informed about the purpose of the study and the methodology of work that would be applied. Only children who have a signed parent's consent are involved in the study. The index $\operatorname{DMF}(\mathrm{T}+\mathrm{t})$ is used to measure the dental health. The DMF $(T+t)$ index is one of the most often used in oral epidemiology to estimate the prevalence of dental caries and the treatment needs of the population. The information necessary for estimating the index is based on the clinical observation of patients with a dental mirror, dental probe, cotton pellets and suction. $\mathrm{DMF}(\mathrm{T}+\mathrm{t})$ represents the sum of the teeth with decay $-\mathrm{D}$, missing teeth (as a result of decay) $-\mathrm{M}$, and those with fillings $-\mathrm{F}, \mathrm{t} / \mathrm{T}-$ teeth. $\mathrm{T}+\mathrm{t}$ is used for mixed dentition. In our study we calculated the $(\mathrm{M})$ - missing teeth of the children in every age group. We considered as prematurely extracted teeth that have been extracted one or more years before the time of their physiological exfoliation. We used a relative share to compare the percentage of prematurely extracted teeth of urban and rural children and chi square test to test the hypothesis that there is a difference in the different groups of prematurely extracted teeth of children. The level of statistical significance is set at alpha level 0.05 .We used a relative share to also compare the reasons of premature tooth loss.

\section{RESULTS AND DISCUSSION}

In this study about $4.6 \%$ of the whole group of examined children are with prematurely extracted primary teeth. There are some differences between the number of prematurely extracted teeth of the urban and rural children (Fig. 1).

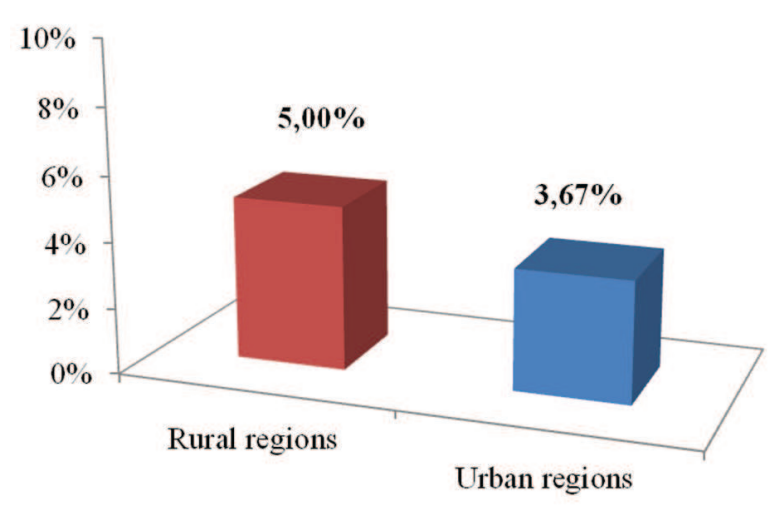

Fig. 1. Relative share of children with prematurely extracted temporary teeth

The results demonstrate a higher number of children with prematurely extracted teeth from rural regions. This could be due to the difficult access of rural children to preventive dental care and respectively higher caries activity. The lack of information available to the parents about the caries prophylaxis during childhood might be another reason. The predominance of prematurely extracted teeth among rural children should determine a strategy for specific prevention in the rural regions. 
There are significant differences between the type of teeth that are prematurely extracted in urban and rural children (Fig. 2).

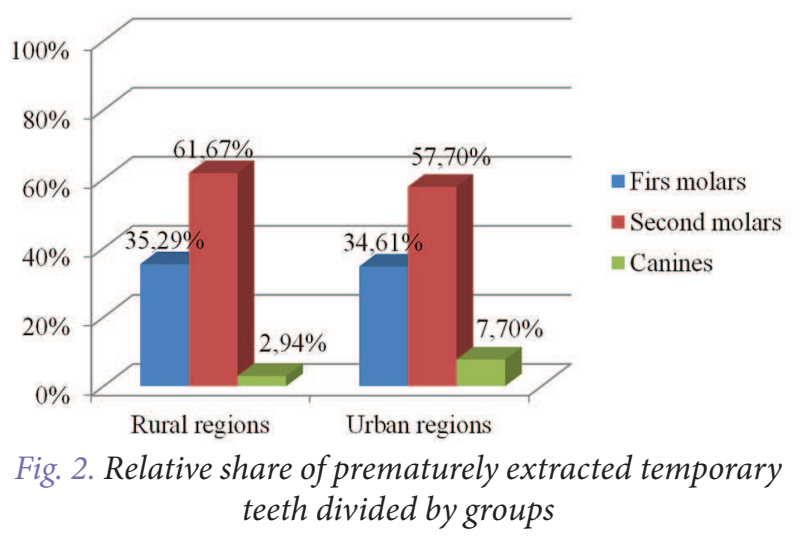

The reason could be because the second primary molars remain longer in the mouth, exposed to the aggressive environmental factors.

Most of the teeth are prematurely extracted because of caries and its complications (Fig. 3).

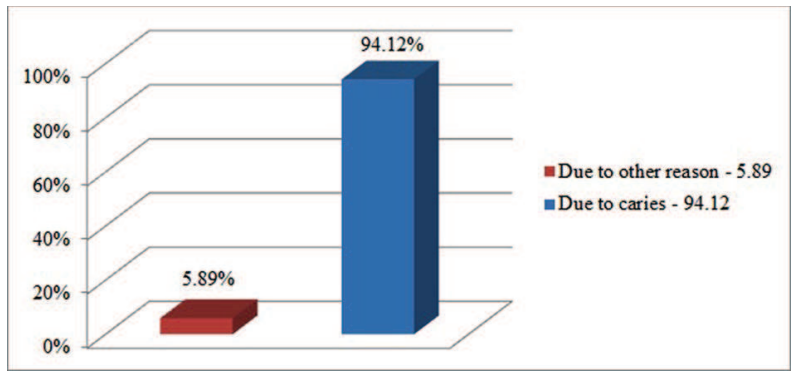

Fig. 3. Relative shares of prematurely extracted temporary teeth by reason for extraction

We found that $4.6 \%$ of the examined school children are with prematurely extracted teeth. The results we obtained in the present study are significantly lower than those reported by other earlier studies $-5.8 \%$ and $6.1 \%(1,2,3)$. Many other authors report higher percentages of prematurely extracted teeth from Istanbul (25\%) (9), Brazil - 9.28\%, Saudi Arabia - 16.5\% (5,6,7,8). Sumare Nema reports that $9.74 \%$ from the examined 1518 children aged between 6 and 9 years are with prematurely extracted teeth (4). The authors explain this finding with the observation that more of the dentists prefer to extract the complicated carious teeth instead of treat- ing them. The other reason for the premature extraction of primary teeth is that some parents neglect the problems with primary teeth, because of their future exfoliation.

The results we obtained demonstrated an increasing number of children with prematurely extracted teeth from the rural regions. This might be due to the difficult access to specialized dental help in these regions and the lack of information available to the parents about caries prophylaxis during childhood. This result is a serious reason for initiating programmes with motivation strategies for children, parents and dentists in order to increase the number of successfully treated cases with caries and decrease complications as a main reason for premature extraction. The predominance of prematurely extracted teeth among the rural children should be a guide for a specific prevention strategy. We found out that the second molars are the most often extracted teeth. They are followed by the first molars. The canines are more rarely prematurely extracted. The different prevalence of caries on different teeth groups could lead to these results. These results are supported by most scientific reports which demonstrates that the premature extraction of the second primary molars is the most frequent one $(9,10,11)$.

Our results differ from others, according to whom the first primary molars are the most often prematurely extracted teeth $(5,12)$. This could be because of the difference between the chronological age of the first and the second primary molars. The first molars appear in the oral cavity earlier and are exposed to the aggressive factors of the oral environment for a longer period of time. Carbohydrates and pathogenic microorganisms are such a factors. On the other hand the dentists prefer to treat the strongly damaged second primary molars with priority in order to maintain the area for the permanent teeth, especially when the first permanent molars have still not erupted. In similar situations the first primary molars are extracted, because of the difficulty of the treatment of complicated caries $(13,14,15,16)$. In his study, Hammad (6) reports that the most often prematurely extracted primary teeth are the upper first primary molars, followed by the lower first primary molars and the upper second primary molars. Ronnerman and other authors conclude that the up- 
Radosveta Andreeva, Hristina Arnautska, Tihomir Georgiev

per first primary molars are the most often extracted teeth $(14,17,18)$.

\section{CONCLUSIONS}

1. The prevalence of premature loss of primary teeth in children aged 6 years is $4.6 \%$.

2. The relative share of prematurely extracted teeth is significantly higher among the rural than the urban children (5\% and 3.67\%, respectively).

3. The second primary molars are the most often prematurely extracted teeth $(61.7 \%$ for rural children; $57.7 \%$ for urban ones), followed by the first primary molars $(35.29 \%$ - rural children; $34.61 \%$ - urban children) and canines $4.49 \%$ and $7.7 \%$ for rural and urban children, respectively).

4. In $94.12 \%$ of the cases, caries and its complications are the main reason for early tooth loss. Dentists have to think more about prevention and adequate treatment of caries in order to avoid premature extraction especially in the rural regions.

\section{REFERENCES:}

1. Ahamed S, Venugopal N, Reddy R. Prevalence of early loss of primary teeth in 59-10-years-old children in Chidambaram town. Contemp Clin Dent. 2012;3(1):27-30.

2. Kelner N, Rodrigues MJ, Miranda K. Prevelance of early loss of desiduous molars in children attending the FOP/UPE in 2002 and 2003. Dent Clin Sci Recife. 2005;4:213-8.

3. Petrunov V. Epidemiolocigal study of the orthodontic deformations and the need of orthodontic treatment among the Bulgarians from the mixed to permanent dentition. Dissertation, Sofia. 2012;35:62-4.

4. Sumare N. The influence of the premature extraction of the primary teeth over the development of the permanent teeth. Avtoreferat. Sofia.1987;6:36-8.

5. Alamoudi N. The prevalence of crowding, attrition, midline discrepancies and early loss in the primary dentition of children in Jeddah Saudi Arabia. J Clin Pediatr Dent. 1999;24:53-8.

6. Hammad N. Space maintainers utilization by 6-7 years old girls in Riyadh Saudi Arabia. J Pak Dent Assoc. 2011;20(1):23-28.
7. Leite-Cavalcanti A, de Alencar B, Benzerra PK, Garcia A. Prevalence of early loss of primary molars in school children in Brazil. Pak Oral Dent J. 2008;28:113-6.

8. Cardoso L, Zemburski C, Fernandes DS. Evaluation of prevalence of precocious loss of desiduous molars. Braz Res Pediatr Dent Integr Clin. 2005;5:17-22.

9. Brothwell DJ. Guidelines on the use of space maintainers following premature loss of primary teeth. J Can Dent Assoc. 1997;63:753-66.

10. Caufield PW, Gutter RG, Dasanayke AP. Initial acquisition of Mutans streptococci by infants. J Dent Res. 1993;72:37-45.

11. Ak G, Sepet E, Pinar A, Aren G, Turan N. Reasons for early loss of primary molars. Oral Health Prev. Dent. 2005;3:113-117.

12. Mahejabeen R, Sudha P. Dental caries prevalence among preschool children of Hubli. J Indian Soc Pedod Prev Dent. 2006;24:19-22.

13. Moss S. Saliva, fluorid, diet, evolution: a new caries model emerge. Italian J. of Pediatric dentistry. 1998;1:19-24.

14. Ronnerman A. The effect of early loss of primary molars on tooth eruption and space conditions. A longitudinal study. Acta Odontol Scand. 1977;35:229-39.

15. Saravanan S, Kalyani V, Jayakodi P. Caries prevalence and the treatment need of rural school shildren,South India. Indian J Dent Res. 2009;19:186-99.

16. Bradford and Airdale Teaching primary care thrast 2006. The oral health of 5 year old children living in Bradfotd and Airdale tPCT. Bradford and Airdale primary care trust.

17. Douglas JM, Wei Y. Caries prevalence and patterns in 3-6 years old children. Community dent. Oral epidemiol. 1995;23:340-343.

18. Schachter $H$. The incidence and effect of premature extraction of deciduous teeth. Br Dental J. 1943;75:57-6. 